\title{
Evaluation of biomass quality of selected woody species depending on the soil enrichment practice**
}

\author{
Mariusz J. Stolarski, Michał Krzyżaniak, Dariusz Załuski, and Dariusz Niksa* \\ Department of Plant Breeding and Seed Production, Faculty of Environmental Management and Agriculture, \\ University of Warmia and Mazury in Olsztyn, Plac Łódzki 3, 10-724 Olsztyn, Poland \\ Received February 9, 2017; accepted August 8, 2017
}

\begin{abstract}
Perennial energy crops are a source of the biomass used to generate energy. The aim of this study was to determine the chemical and thermophysical parameters of short rotation woody crops (black locust, poplar and willow), depending on soil enrichment practice (mineral fertilisation, lignin and mycorrhiza), in three- and four-year harvest cycles. In the study, the thermophysical properties and elemental composition of the biomass were determined. All analyses were performed in triplicate according to the standards. The fresh black locust biomass had the lowest moisture content, which resulted in the best lower heating value (10.16 $\mathrm{MJ} \mathrm{kg}^{-1}$, on average) in the four-year harvest cycle. The poplar biomass had the greatest higher heating value, fixed carbon, carbon and ash content, the highest concentrations of which were found in the biomass in which lignin was applied $(2.00 \%$ d.m.). On the other hand, the willow biomass contained the lowest concentrations of ash and fixed carbon. Soil enrichment significantly differentiated the quality parameters of black locust, poplar and willow. This effect is of particular importance to those who grow and use biomass as a fuel.

Keyw ords: willow, black locust, poplar, lower heating value, chemical composition
\end{abstract}

\section{INTRODUCTION}

Instability in the global fossil fuels markets, the need to reduce greenhouse gas emissions, as well as a greater environmental awareness, in recent years have resulted in a rapid development of renewable energy sources (RES). The most important of these is the biomass used to generate bioenergy, which provides $10 \%$ of the world primary energy supply (IEA, 2016). Bioenergy accounts for up to

*Corresponding author e-mail: dariusz.niksa@uwm.edu.pl **This work has been financed by the strategic program of the National (Polish) Centre for Research and Development (NCBiR): "Advanced Technologies for Energy Generation. Task 4: Elaboration of Integrated Technologies for the Production of Fuels and Energy from Biomass, Agricultural Waste and other Waste Materials" and Department of Plant Breeding and Seed Production statutory sources, 2010-2015. two-thirds of all RES in Europe, and it grows at a rate similar to that of all the other sources combined (AEBIOM, 2015). Another consequence of this is an increased scientific interest in lignocellulosis biomass, resulting in abundant literature on the subject (Mitsui et al., 2010; Weger et al., 2013; Sabatti et al., 2014; Manzone et al., 2015; Stolarski et al., 2015b; Matyka and Kuś, 2016).

Perennial energy crops are among the sources of the biomass used to generate energy. These include crops grown as short rotation (SRCs), short rotation woody crops (SRWCs), and, in some cases, short rotation forestry (SRF) (Slade et al., 2011). Fast-growing woody species, such as willow, poplar or black locust are attractive sources of renewable energy, and are grown mostly in a short rotation system, i.e. in a harvesting rotation period of 1-7 years (Di Muzio Pasta et al., 2007). SRWCs have some obvious advantages over food crops, namely, smaller requirements related to soil quality or to fertilisation, and they do not require intensive protection against agrophages (Njakou Djomo et al., 2013). Furthermore, such crops bring a number of environmental benefits, e.g. they improve soil properties, reduce soil erosion and sequester soil organic carbon (Blanco-Canqui, 2010). However, it must be emphasised that perennial energy crops are grown mainly with a view to obtaining renewable energy. SRWCs biomass can be used traditionally to produce heat and electricity by combustion or gasification, and,- owing to their rich chemical composition - has enormous potential in the chemical industry (Krzyżaniak et al., 2014).

Plantations of SRWCs should be run in such a way as to achieve not only high but also good quality of biomass yield in order to obtain energy, environmental and economic benefits. Wood contains about $50 \%$ of carbon, $44 \%$ of oxygen and $6 \%$ of hydrogen, along with a relatively small amount

(C) 2018 Institute of Agrophysics, Polish Academy of Sciences 
of sulphur and nitrogen (Fengel and Wegener, 1989). In addition, biomass quality is also determined by its higher heating value (HHV), lower heating value (LHV), moisture and ash content. The effect of fertilisation on the amount of biomass, the energy value of biomass and its being one of the factors affecting the energy efficiency of SRWCs has been examined in numerous studies (Njakou Djomo et al., 2015; Stolarski et al., 2015b). However, as has been mentioned before, the yield quality, which can be affected by fertilisation, is also important. Therefore, the aim of this study was to determine the chemical and thermophysical parameters of SRWCs of black locust, poplar and willow, depending on the soil enrichment practice applied.

\section{MATERIALS AND METHODS}

This study was based on a three-factorial field trial run in the years 2010-2013 at the Educational and Research Station in Łężany belonging to the University of Warmia and Mazury in Olsztyn. The soil used was of a low usability for conventional food or fodder crops production. The experiment was set up in brunic arenosol (Dystric) soil formed from sand. There was slightly loamy sand in the A horizon (topsoil) $(0-21 \mathrm{~cm})$ and in the $\mathrm{Bv}$ horizon (21$41 \mathrm{~cm})$, and sand in the bedrock horizon $C(41-150 \mathrm{~cm})$. The content of clay fraction $(\varnothing<0.002 \mathrm{~mm})$ in the different soil horizons did not exceed $2 \%$. The soil was periodically too dry, and the level of underground water was much below $150 \mathrm{~cm}$. The soil $\mathrm{pH}$ was neutral-to-alkaline $(\mathrm{pH}$ $\mathrm{KCl}$ 6.3-7.9).

The experiment was established in a split-plot design. Three plant species were the first experiment factor; (A) species black locust (Robinia pseudoacacia), poplar Populus nigra x P. Maximowiczii Henry cv. Max-5 and willow of the Salix viminalis; planted at the density of 11.11 thousand per ha. The second experimental factor (B) was the method of soil enrichment, which used lignin, mineral fertilisation, mycorrhiza inoculation and no soil enrichment (control plot). The third experimental factor (C) was the harvest cycle: three- or four-year.

Lignin $\left(13.3 \mathrm{Mg} \mathrm{ha}^{-1}\right)$ was scattered on the soil surface with a trailer fertiliser spreader in spring 2010, before the experiment was set up. Live mycorrhizal mycelium (30-35 $\mathrm{cm}^{3}$ under each plant) was applied with a manual applicator in early September 2010. Mineral fertilisers (N, P, K: 90, 13, and $50 \mathrm{~kg} \mathrm{ha}^{-1}$, respectively) were spread by hand before and on the beginning of the second growing season (2011).

All growing periods (April-October) from 2010 to 2013 were warmer than the multi-year period (1998-2007) by 0.2 to $0.9^{\circ} \mathrm{C}$, except 2012 , when the temperature was the same as in $1998-2007\left(13.5^{\circ} \mathrm{C}\right)$. The amount of rainfall in 2010 was higher than the multi-year average both during the whole year $(752 \mathrm{~mm})$ and during the vegetation period $(527 \mathrm{~mm})$. However, its distribution was uneven, because low rainfall in April 2010 (17 $\mathrm{mm})$ had a particularly negative effect on how well the seedlings of black locust took root. The total rainfall in subsequent growing periods $(447-613 \mathrm{~mm})$ were rather beneficial for the plant growth. Detailed information on setting up and running the experiment is provided in the paper by Stolarski et al. (2015b).

In December 2012 and 2013, three- and four-year old coppices were felled from the different soil enrichment methods and the control plot. The plants were cut down with a chain saw (Makita DCS520), 5-10 cm above the ground level. Then, the whole shoots with branches were chipped with a Junkkari HJ 10 G (Junkkari) chipper. While chipping shoots, approx. $5 \mathrm{~kg}$ biomass samples (packed in foil bags) for each method of soil enrichment were taken for laboratory analyses.

Biomass samples delivered from field trials were mixed and laboratory samples were isolated for analyses. The thermophysical and chemical properties of each species were determined in each year in three replications: moisture content with the oven-dry method (ISO 18134-1:2015); higher heating value (HHV) with the dynamic method (ISO 1928:2009); the lower heating value (LHV) of biomass calculated according to Kopetz et al. (2007); volatile matter, fixed carbon and ash in the thermogravimetric analyser according to ISO 18122:2015; the carbon, hydrogen and sulphur content in the dry biomass determined via an automatic analyser (ISO 16948:2015 and 16994:2015); the nitrogen content determined by the Kjeldahl method. The detailed methodology of laboratory analyses is described in Stolarski et al. (2016).

A three-way analysis of variance was performed to examine the fixed effects of species (factor A), soil enrichment (factor B), harvest cycle (factor C), and their interactions. The Tukey (HSD) multiple test (at $\mathrm{p}<0.05$ ) was used to determine homogeneous groups for the examined features.

The Principal Component Analysis (PCA) was performed to assess the chemical parameters of the biomass. The diagram of the Component Scores for the first two PCs (F1 and F2) was presented as a biplot. The data were analysed statistically using the STATISTICA 12 PL software.

\section{RESULTS AND DISCUSSION}

The thermophysical and chemical properties of the biomass under analysis varied with respect to the analysed factors and their interactions (Table 1). The differences in the parameters under study were considered significant at the 0.01 level.

The moisture content in the biomass was significantly differentiated by species, harvest cycle and interaction between these factors, but soil enrichment was insignificant (Table 2). The lowest moisture content (MC) was found in the black locust biomass in a four-year harvest cycle (on average $42.09 \%$ ), and it was significantly lower 
Table 1. Fixed effects and their significance levels for ten dependent variables

\begin{tabular}{|c|c|c|c|c|c|c|c|c|c|c|}
\hline Source of variation & Moisture & Ash & $\begin{array}{c}\text { Higher } \\
\text { heating } \\
\text { value }\end{array}$ & $\begin{array}{c}\text { Lower } \\
\text { heating } \\
\text { value }\end{array}$ & $\begin{array}{l}\text { Volatile } \\
\text { matter }\end{array}$ & $\begin{array}{l}\text { Fixed } \\
\text { carbon }\end{array}$ & $\mathrm{C}$ & $\mathrm{H}$ & $\mathrm{S}$ & $\mathrm{N}$ \\
\hline Species (A) & $* *$ & $* *$ & $* *$ & $* *$ & $* *$ & $* *$ & $* *$ & $* *$ & $* *$ & $* *$ \\
\hline Soil enrichment (B) & ns & $* *$ & $*$ & ns & $* *$ & $* *$ & $* *$ & $* *$ & ns & ** \\
\hline Harvest cycle (C) & $* *$ & $* *$ & ns & $* *$ & ns & $* *$ & $* *$ & $* *$ & $* *$ & ** \\
\hline $\mathrm{AB}$ & ns & $* *$ & $* *$ & ns & $* *$ & $* *$ & $* *$ & $* *$ & $* *$ & ** \\
\hline $\mathrm{AC}$ & $* *$ & $* *$ & $* *$ & $* *$ & $* *$ & $* *$ & $* *$ & $* *$ & $* *$ & ** \\
\hline $\mathrm{BC}$ & ns & $* *$ & $*$ & ns & $* *$ & $* *$ & $* *$ & $* *$ & $* *$ & ** \\
\hline $\mathrm{ABC}$ & ns & $* *$ & $* *$ & ns & $* *$ & $* *$ & $* *$ & $* *$ & $* *$ & $* *$ \\
\hline
\end{tabular}

Significant at the levels: $* 0.05, * * 0.01 ; \mathrm{ns}-$ not significant.

Table 2. Moisture and ash content in SRWCs biomass

\begin{tabular}{|c|c|c|c|c|c|}
\hline \multirow{3}{*}{ Species (A) } & \multirow{3}{*}{ Soil enrichment (B) } & \multicolumn{4}{|c|}{ Harvest cycle (C) } \\
\hline & & Three-year & Four-year & Three-year & Four-year \\
\hline & & \multicolumn{2}{|c|}{ Moisture content $(\%)$} & \multicolumn{2}{|c|}{ Ash content (\% d.m.) } \\
\hline \multirow{4}{*}{ Black locust } & Control & $47.03 \pm 0.47$ & $42.21 \pm 0.71$ & $1.31 \pm 0.07 \mathrm{e}$ & $1.44 \pm 0.07 \mathrm{de}$ \\
\hline & Lignin & $46.86 \pm 0.55$ & $42.02 \pm 0.18$ & $1.30 \pm 0.03 \mathrm{e}$ & $1.57 \pm 0.05 \mathrm{~cd}$ \\
\hline & Mineral fertilization & $47.00 \pm 0.56$ & $41.88 \pm 0.67$ & $1.61 \pm 0.01 \mathrm{c}$ & $1.57 \pm 0.07 \mathrm{~cd}$ \\
\hline & Mycorrhiza & $47.04 \pm 0.16$ & $42.25 \pm 0.02$ & $1.60 \pm 0.05 \mathrm{~cd}$ & $1.43 \pm 0.05 \mathrm{de}$ \\
\hline Mean & & $46.98 \pm 0.40 \mathrm{D}$ & $42.09 \pm 0.45 \mathrm{E}$ & $1.46 \pm 0.16 \mathrm{BC}$ & $1.50 \pm 0.09 \mathrm{~B}$ \\
\hline \multirow{4}{*}{ Poplar } & Control & $52.74 \pm 0.057$ & $55.70 \pm 0.20$ & $1.65 \pm 0.05 \mathrm{c}$ & $1.61 \pm 0.02 \mathrm{~cd}$ \\
\hline & Lignin & $53.26 \pm 0.13$ & $55.78 \pm 0.67$ & $1.95 \pm 0.05 \mathrm{a}$ & $2.00 \pm 0.02 \mathrm{a}$ \\
\hline & Mineral fertilization & $53.21 \pm 0.49$ & $55.77 \pm 0.45$ & $1.75 \pm 0.02 \mathrm{bc}$ & $1.79 \pm 0.02 \mathrm{~b}$ \\
\hline & Mycorrhiza & $52.65 \pm 0.58$ & $55.72 \pm 0.29$ & $1.81 \pm 0.01 \mathrm{~b}$ & $1.79 \pm 0.02 \mathrm{~b}$ \\
\hline Mean & & $52.97 \pm 0.50$ B & $55.74 \pm 0.38 \mathrm{~A}$ & $1.79 \pm 0.12 A$ & $1.80 \pm 0.15 A$ \\
\hline \multirow{4}{*}{ Willow } & Control & $49.98 \pm 0.29$ & $50.39 \pm 0.19$ & $1.50 \pm 0.01 \mathrm{~d}$ & $1.20 \pm 0.09$ ef \\
\hline & Lignin & $50.63 \pm 0.30$ & $50.52 \pm 0.41$ & $1.48 \pm 0.01 \mathrm{~d}$ & $1.22 \pm 0.04 \mathrm{ef}$ \\
\hline & Mineral fertilization & $50.19 \pm 0.05$ & $50.17 \pm 0.13$ & $1.31 \pm 0.01 \mathrm{e}$ & $1.16 \pm 0.03 \mathrm{f}$ \\
\hline & Mycorrhiza & $50.86 \pm 0.56$ & $50.34 \pm 0.50$ & $1.46 \pm 0.04 \mathrm{~d}$ & $1.15 \pm 0.01 \mathrm{f}$ \\
\hline Mean & & $50.42 \pm 0.47 \mathrm{C}$ & $50.36 \pm 0.32 \mathrm{C}$ & $1.43 \pm 0.08 \mathrm{C}$ & $1.18 \pm 0.05 \mathrm{D}$ \\
\hline
\end{tabular}

Explanation as in Table 1.

than in the three-year cycle by about 4.89 p.p. The poplar biomass had the highest MC and this parameter was significantly lower in the three-year than in the four-year cycle (2.77 p.p. less on average). For the willow, the harvest cycle did not have a significant effect on MC. Similar levels of $\mathrm{MC}$ were found in the black locust, poplar and willow biomass after the second year of growth (Stolarski et al., 2013a). It has been shown in other studies that biomass $\mathrm{MC}$ also depends on harvest time and harvest conditions (Stolarski et al., 2013b). A relatively low MC of black locust $(40 \%)$ was obtained in the warmer climate conditions of Italy (Gasol et al., 2010). However, the willow 
biomass has a higher MC, which is usually about 50\%, as in this study (Mitsui et al., 2010; Krzyżaniak et al., 2014). On the other hand, $\mathrm{MC}$ in the poplar biomass can exceed 60\% (Sabatti et al., 2014).

With regard to ash content, all experimental factors differentiated the parameter significantly (Table 2). The lowest ash content was found in the willow biomass on the plot where mycorrhiza was used and the plants were grown in a four-year rotation cycle $(1.15 \%$ d.m.). A combination of lignin fertilisation in a three-year rotation cycle proved to be the best for black locust, and it was almost equal to the control (only 0.01 p.p. difference). The highest ash content was found for the poplar biomass $(1.80 \%$ d.m. on average). The lowest ash content was found in the biomass of this species on the control plot in the four-year rotation cycle ( $1.61 \%)$. This was 0.14 p.p. lower than in the best option with fertilisation $(1.75 \% \mathrm{~d} . \mathrm{m}$. in the mineral fertilisation object). The highest ash content in the poplar biomass was found on the plot with lignin, which increased the ash content by about $24 \%$ as compared to the control The differences in ash content in the black locust, poplar and willow biomass on plots with soil enrichment as compared to the control ranged from -1 to 23,6 to 24 , and -13 to $2 \%$, respectively. In the previous study, the mean ash content in the black locust, poplar and willow biomass harvested in the two-year rotation cycle were higher than in this study by $0.62,0.21$ and 0.23 p.p., respectively (Stolarski et al., 2013a). Straker et al. (2015) reviewed the existing literature and reported that ash content in the black locust biomass can range widely $(0.17-2.2 \%$ d.m.). The ash content in the poplar biomass in the two-year harvest rotation cycle also varied highly (0.98-3.12\% d.m.) depending on the genotype (Sabatti et al., 2014). Furthermore, in a study of different clones of willow harvested in the three-year rotation cycle, Krzyżaniak et al. (2014) found differences in the ash content to be smaller (1.04-1.60\% d.m.).

The SRWCs biomass can contain several times less ash than the straw or grass biomass (Greenhalf et al., 2012; Lalak et al., 2016). Still, compared to coal, ash content in woody biomass can be up to a dozen times lower (Bowen and Irwin, 2008; Dincer and Zamfirescu, 2014). This results in higher proportions of energy obtained from this fuel, and the remaining ash which meets the quality standards can be used as valuable soil enrichment (Freire et al., 2015). With regard to the $\mathrm{HHV}$, only the harvest cycle did not have a significant impact on the results. The differences resulting from soil enrichment were significant in all species. The highest HHVs were found for the poplar biomass in the four-year harvest cycle (on average, $19.93 \mathrm{MJ} \mathrm{kg}^{-1}$ d.m.) (Table 3). Fertilisation did not affect HHV in this species in the four-year harvest rotation cycle, but the highest levels in the three-year harvest cycle were found on the plots with mineral fertilisation and mycorrhiza. Significantly lower HHVs were found for the willow biomass - on average from 0.19 to $0.37 \mathrm{MJ} \mathrm{kg}^{-1} \mathrm{~d}$.m. less than the poplar biomass in the three-year and four-year harvest cycle, respectively. The significantly lowest HHVs were found in the black locust biomass. The lowest HHV in this species was determined on the plot with lignin in the four-year harvest cycle (19.22 $\left.\mathrm{MJ} \mathrm{kg}^{-1} \mathrm{~d} . \mathrm{m}\right)$. Differences in HHVs for the black locust, poplar and willow biomass on plots with soil enrichment, compared to the control plots, ranged from -0.3 to $0.8 ;-0.03$ to 1 , and -0.8 to $0.2 \%$, respectively.

In contrast, the opposite inter-species differences were observed in the LHVs, when compared to HHVs, which can be attributed to the moisture content in the biomass. Therefore, the black locust biomass had the highest LHVs among the species under study in both rotation cycle options (9.17 and $10.16 \mathrm{MJ} \mathrm{kg}^{-1}$ on average) (Table 3 ). The highest LHV in this species was found on the plot with mineral fertilisation in the four-year rotation cycle $(10.27 \mathrm{MJ}$ $\left.\mathrm{kg}^{-1}\right)$. Significantly lower LHVs were found for the willow biomass. The biomass in the control plots had the highest LHVs in both rotation options. With regard to the plots with fertilisation, the best plot was the one where mineral fertilisation was applied, in which the LHV in the four-year harvest cycle was as high as in the control $\left(8.51 \mathrm{MJ} \mathrm{kg}^{-1}\right)$. Furthermore, the poplar biomass had the significantly lowest LHVs in both harvest cycles. In contrast to black locust, the poplar biomass in the four-year rotation cycle had significantly lower LHVs than in the three-year rotation cycle.

HHVs and LHVs of fresh biomass as found in this study are typical of the species under analysis and are close to the findings of other studies (Krzyżaniak et al., 2014; Sabatti et al., 2014; Stolarski et al., 2013a). It is especially important that LHV should be as high as possible when energy from biomass is generated in the thermal conversion process. This parameter can be increased by storing fresh biomass under conditions which help to decrease the moisture content, because in wet biomass energy produced by combustion is consumed in evaporating moisture from the material, thus reducing the usable energy available or the LHV (Acquah et al., 2015). It was shown in a different study that extending the period of the willow biomass storage in bales resulted in a decrease in the moisture content from $53.60 \%$ in January to $17.48 \%$ in September. Furthermore, the LHV increased during this period from 7.75 to $15.65 \mathrm{MJ} \mathrm{kg}^{-1}$ (Stolarski et al., 2015a). However, the values were comparable only to low-quality coal (Dincer and Zamfirescu, 2014).

As with HHV, volatile matter content was not differentiated significantly by the harvest cycle alone; the other factors and interactions between these were significant for the parameter. The significantly highest volatile matter (VM) content was found in the willow biomass (Table 4). Within this species, the highest VM content was found in biomass grown in objects with mycorrhizal inoculation and lignin application in the four-year harvest cycle (79.84, $79.83 \%$ d.m., respectively). Slightly lower values of the parameter were found for the black locust biomass, and the 
Table 3. Higher heating value and lower heating value in SRWCs biomass

\begin{tabular}{|c|c|c|c|c|c|}
\hline \multirow{3}{*}{ Species (A) } & \multirow{3}{*}{ Soil enrichment (B) } & \multicolumn{4}{|c|}{ Harvest cycle (C) } \\
\hline & & Three-year & Four-year & Three-year & Four-year \\
\hline & & \multicolumn{2}{|c|}{ Higher heating value ( $\mathrm{MJ} \mathrm{kg}^{-1}$ d.m.) } & \multicolumn{2}{|c|}{ Lower heating value $\left(\mathrm{MJ} \mathrm{kg}^{-1}\right)$} \\
\hline \multirow{4}{*}{ Black locust } & Control & $19.40 \pm 0.07$ ef & $19.27 \pm 0.01 \mathrm{f}$ & $9.13 \pm 0.08$ & $10.10 \pm 0.15$ \\
\hline & Lignin & $19.48 \pm 0.14 \mathrm{~d}$ & $19.22 \pm 0.04 \mathrm{f}$ & $9.21 \pm 0.20$ & $10.12 \pm 0.01$ \\
\hline & Mineral fertilization & $19.50 \pm 0.08 \mathrm{~cd}$ & $19.43 \pm 0.04 \mathrm{e}$ & $9.19 \pm 0.16$ & $10.27 \pm 0.14$ \\
\hline & Mycorrhiza & $19.46 \pm 0.03 \mathrm{de}$ & $19.38 \pm 0.03$ ef & $9.16 \pm 0.02$ & $10.16 \pm 0.01$ \\
\hline Mean & & $19.46 \pm 0.09 \mathrm{D}$ & $19.32 \pm 0.09 \mathrm{E}$ & $9.17 \pm 0.12 \mathrm{~B}$ & $10.16 \pm 0.11 \mathrm{~A}$ \\
\hline \multirow{4}{*}{ Poplar } & Control & $19.66 \pm 0.04 \mathrm{c}$ & $19.96 \pm 0.01 \mathrm{a}$ & $8.00 \pm 0.11$ & $7.48 \pm 0.05$ \\
\hline & Lignin & $19.76 \pm 0.01 \mathrm{bc}$ & $19.94 \pm 0.02 \mathrm{a}$ & $7.94 \pm 0.03$ & $7.46 \pm 0.15$ \\
\hline & Mineral fertilization & $19.85 \pm 0.01 \mathrm{~b}$ & $19.92 \pm 0.04 \mathrm{ab}$ & $7.99 \pm 0.11$ & $7.45 \pm 0.09$ \\
\hline & Mycorrhiza & $19.85 \pm 0.10 \mathrm{~b}$ & $19.91 \pm 0.05 \mathrm{ab}$ & $8.11 \pm 0.09$ & $7.46 \pm 0.07$ \\
\hline Mean & & $19.78 \pm 0.09 \mathrm{~B}$ & $19.93 \pm 0.03 A$ & $8.01 \pm 0.10 \mathrm{D}$ & $7.46 \pm 0.08 \mathrm{E}$ \\
\hline \multirow{4}{*}{ Willow } & Control & $19.63 \pm 0.08 \mathrm{c}$ & $19.63 \pm 0.04 \mathrm{c}$ & $8.60 \pm 0.09$ & $8.51 \pm 0.04$ \\
\hline & Lignin & $19.55 \pm 0.09 \mathrm{~cd}$ & $19.54 \pm 0.03 \mathrm{~cd}$ & $8.42 \pm 0.07$ & $8.44 \pm 0.07$ \\
\hline & Mineral fertilization & $19.48 \pm 0.05 \mathrm{~d}$ & $19.54 \pm 0.02 \mathrm{~cd}$ & $8.48 \pm 0.04$ & $8.51 \pm 0.04$ \\
\hline & Mycorrhiza & $19.67 \pm 0.05 \mathrm{c}$ & $19.51 \pm 0.01 \mathrm{~cd}$ & $8.43 \pm 0.10$ & $8.46 \pm 0.12$ \\
\hline Mean & & $19.59 \pm 0.10 \mathrm{C}$ & $19.56 \pm 0.05 \mathrm{C}$ & $8.48 \pm 0.10 \mathrm{C}$ & $8.48 \pm 0.07 C$ \\
\hline
\end{tabular}

Explanation as in Table 1.

highest value was found for plots with lignin fertilisation in both harvest cycles (78.54 and $78.98 \%$ d.m.). The significantly lowest VM content was found in the poplar biomass. In all of the plots where the soil was enriched, the biomass of the species in the three-year harvest cycle contained lower values of volatile matter compared to the control. The content of this parameter was higher in all of the plots where soil was enriched and where the crops were grown in the four-year rotation cycle - a maximum of $77.77 \%$ d.m. on the plot with mycorrhizal inoculation. The differences in the VM content in the black locust, poplar and willow biomass on plots where soil was enriched, compared to the control plots, ranged from -0.8 to $1.6,-0.9$ to 0.9 , and -0.7 to $0.7 \%$, respectively. The volatile matter content in black locust, poplar and willow were slightly higher in this study than in the previous study in a two-year harvest cycle (Stolarski et al., 2013a). According to the findings of other studies, volatile matter content in biomass (in most cases) is between 70 and $80 \%$. This is 2 to 4 times higher compared to coal, and the parameter is significant because it determines how easily biomass can be gasified (Jameel et al., 2010).
On the other hand, fixed carbon content was significantly affected by all of the experimental factors and interactions between them. The significantly highest level of this parameter was found in the black locust biomass on the plot where micorrhizal inoculation was applied, as well as for poplar in the control $(21.29 \%$ d.m.), both of these in the four-year harvest cycle (Table 4). The lowest mean values of fixed carbon were found in the willow biomass, regardless of the harvest cycle. The lowest value of this parameter in all the species was also found in the willow biomass $(18.95 \%$ d.m.) on the plot where lignin was applied in the four-year harvest cycle. This is an opposite effect of lignin on the fixed carbon content in the willow biomass to that demonstrated in the two-year cycle, where the level of the parameter $(20.70 \%$ d.m.) was the most beneficial to the plot with this type of soil enrichment (Stolarski et al., 2013a). In contrast, only small differences in the fixed carbon content were observed in the other species compared to the study. Furthermore, the differences in the fixed carbon content in black locust, poplar and the willow biomass on plots where soil was enriched, compared to the control plots, were -6.5 to $2.3,-4$ to 2.8 , and -2.8 to $2.9 \%$, respectively. 
Table 4. Volatile matter and fixed carbon content in SRWC biomass

\begin{tabular}{|c|c|c|c|c|c|}
\hline \multirow{3}{*}{ Species (A) } & \multirow{3}{*}{ Soil enrichment (B) } & \multicolumn{4}{|c|}{ Harvest cycle (C) } \\
\hline & & Three-year & Four-year & Three-year & Four-year \\
\hline & & \multicolumn{2}{|c|}{ Volatile matter ( $\%$ d.m.) } & \multicolumn{2}{|c|}{ Fixed carbon (\% d.m.) } \\
\hline \multirow{4}{*}{ Black locust } & Control & $78.41 \pm 0.17 \mathrm{bc}$ & $77.75 \pm 0.08 \mathrm{~d}$ & $19.98 \pm 0.10 \mathrm{c}$ & $20.82 \pm 0.10 \mathrm{ab}$ \\
\hline & Lignin & $78.54 \pm 0.03 \mathrm{~b}$ & $78.98 \pm 0.39 b$ & $19.89 \pm 0.06 \mathrm{c}$ & $19.46 \pm 0.43 \mathrm{~d}$ \\
\hline & Mineral fertilization & $77.77 \pm 0.02 \mathrm{~d}$ & $78.03 \pm 0.15 \mathrm{c}$ & $20.27 \pm 0.03 \mathrm{~b}$ & $20.40 \pm 0.10 \mathrm{~b}$ \\
\hline & Mycorrhiza & $78.17 \pm 0.02 \mathrm{c}$ & $77.29 \pm 0.09$ ef & $19.97 \pm 0.02 \mathrm{c}$ & $21.29 \pm 0.14 \mathrm{a}$ \\
\hline \multirow[t]{2}{*}{ Mean } & & $78.22 \pm 0.32 \mathrm{~B}$ & $78.01 \pm 0.67 \mathrm{BC}$ & $20.03 \pm 0.16 \mathrm{C}$ & $20.49 \pm 0.73 \mathrm{~B}$ \\
\hline & Control & $78.18 \pm 0.13 \mathrm{c}$ & $77.11 \pm 0.32 \mathrm{f}$ & $19.79 \pm 0.08 \mathrm{c}$ & $21.29 \pm 0.34 \mathrm{a}$ \\
\hline \multirow{3}{*}{ Poplar } & Lignin & $77.69 \pm 0.20 \mathrm{~d}$ & $77.44 \pm 0.44 \mathrm{de}$ & $19.98 \pm 0.14 \mathrm{c}$ & $20.56 \pm 0.43 b$ \\
\hline & Mineral fertilization & $77.62 \pm 0.01 \mathrm{de}$ & $77.41 \pm 0.17 \mathrm{e}$ & $20.21 \pm 0.02 \mathrm{bc}$ & $20.80 \pm 0.18 \mathrm{ab}$ \\
\hline & Mycorrhiza & $77.48 \pm 0.23 \mathrm{de}$ & $77.77 \pm 0.26 \mathrm{~cd}$ & $20.34 \pm 0.24 b$ & $20.44 \pm 0.29 b$ \\
\hline \multirow[t]{2}{*}{ Mean } & & $77.74 \pm 0.31 \mathrm{BC}$ & $77.43 \pm 0.36 \mathrm{C}$ & $20.08 \pm 0.25 \mathrm{C}$ & $20.77 \pm 0.43 \mathrm{~A}$ \\
\hline & Control & $79.14 \pm 0.65 \mathrm{ab}$ & $79.30 \pm 0.11 \mathrm{ab}$ & $19.46 \pm 0.13 \mathrm{~d}$ & $19.50 \pm 0.02 \mathrm{~cd}$ \\
\hline \multirow{3}{*}{ Willow } & Lignin & $78.57 \pm 0.18 \mathrm{~b}$ & $79.83 \pm 0.26 \mathrm{a}$ & $19.47 \pm 0.17 \mathrm{~d}$ & $18.95 \pm 0.23 \mathrm{e}$ \\
\hline & Mineral fertilization & $78.70 \pm 0.11 \mathrm{~b}$ & $78.78 \pm 0.27 \mathrm{~b}$ & $19.56 \pm 0.11 \mathrm{~cd}$ & $20.06 \pm 0.24 \mathrm{c}$ \\
\hline & Mycorrhiza & $78.19 \pm 0.09 \mathrm{c}$ & $79.84 \pm 0.32 \mathrm{a}$ & $20.02 \pm 0.05 \mathrm{c}$ & $19.01 \pm 0.32 \mathrm{de}$ \\
\hline Mean & & $78.65 \pm 0.46 \mathrm{~A}$ & $79.44 \pm 0.50 \mathrm{~A}$ & $19.63 \pm 0.26 \mathrm{D}$ & $19.38 \pm 0.51 \mathrm{D}$ \\
\hline
\end{tabular}

Explanation as in Table 1.

The elemental composition of the biomass of the species under study was differentiated significantly by all the experimental factors and interactions between them, except for sulphur, whose content was not significantly affected by soil enrichment (Tables 5 and 6).

The significantly highest carbon content was found in the poplar biomass, regardless of the harvest cycle (Table 5). The highest carbon content in this species was found in the biomass on the plot fertilised by lignin in both harvest cycles (52.34 and $51.55 \%$ d.m.). Significantly lower values of the element were found in willow biomass, and the highest $\mathrm{C}$ content was found on the plot with mineral fertilisation in the three-year harvest cycle $(51.25 \%$ d.m.). All of the soil enrichment practices caused a significant increase in the carbon content in the willow biomass in the three-year harvest cycle, whereas the opposite effect was observed in the four-year cycle.

On the other hand, black locust contained the significantly lowest carbon content (50.11 and $49.80 \%$ d.m., on average). As in poplar, the highest carbon content in the three-year harvest cycle was found in biomass on the plot where lignin was used as a fertiliser, whereas the highest carbon values in the four-year harvest cycle were found in biomass harvested in the control plot and in that where mycorrhizal inoculation was applied (50.07 and 50.06\% d.m., respectively).

The differences in carbon content in the black locust, poplar and willow biomass on plots where soil enrichment was applied, compared to the control plots, were -2.3 to $0.004,-0.8$ to 1.2 , and -1.3 to $1.6 \%$, respectively. A similar carbon content in the willow biomass in the three and four-year rotation cycle has been found in earlier studies (Krzyżaniak et al., 2014; Stolarski et al., 2013b). Furthermore, the willow, black locust and poplar biomass in the two-year cycle contained higher levels of the element, by $0.3,0.7$ and 0.8 p.p. d.m. more in the three-year harvest cycle, and by $0.45,1.01$ and 1.69 p.p. d.m., in the four-year, respectively (Stolarski et al., 2013a). Together, oxygen and carbon are the main biomass components which affect the HHV (Obernberger et al., 2006). The SRWCs biomass contains from approx. 1.5 to 12 p.p. more $\mathrm{C}$ than other types of biomass (Jenkins et al., 1998), but approx. 13 p.p. less than bituminous coal (Cuiping et al., 2004) and as much as 35-47 p.p. less than anthracite (Bowen and Irwin, 2008).

The highest hydrogen content was found in the biomass of all the species in the three-year harvest cycle (Table 5). The highest $\mathrm{H}$ value was found in the black locust biomass 
Table 5. $\mathrm{C}$ and $\mathrm{H}$ content in SRWC biomass

\begin{tabular}{|c|c|c|c|c|c|}
\hline \multirow{3}{*}{ Species (A) } & \multirow{3}{*}{ Soil enrichment (B) } & \multicolumn{4}{|c|}{ Harvest cycle (C) } \\
\hline & & Three-year & Four-year & Three-year & Four-year \\
\hline & & \multicolumn{2}{|c|}{$\mathrm{C}(\%$ d.m.) } & \multicolumn{2}{|c|}{ H (\% d.m.) } \\
\hline \multirow{4}{*}{ Black locust } & Control & $50.68 \pm 0.05 \mathrm{~d}$ & $50.07 \pm 0.21 \mathrm{ef}$ & $6.29 \pm 0.01 \mathrm{ab}$ & $5.82 \pm 0.03 \mathrm{gh}$ \\
\hline & Lignin & $50.86 \pm 0.05 \mathrm{c}$ & $49.76 \pm 0.13 \mathrm{f}$ & $6.37 \pm 0.04 \mathrm{a}$ & $5.85 \pm 0.05 \mathrm{~g}$ \\
\hline & Mineral fertilization & $49.50 \pm 0.21 \mathrm{fg}$ & $49.33 \pm 0.12 \mathrm{~g}$ & $6.13 \pm 0.06 \mathrm{~cd}$ & $5.88 \pm 0.02 \mathrm{~g}$ \\
\hline & Mycorrhiza & $49.41 \pm 0.34 \mathrm{fg}$ & $50.06 \pm 0.21$ ef & $5.96 \pm 0.01 \mathrm{f}$ & $6.03 \pm 0.04$ ef \\
\hline \multirow[t]{2}{*}{ Mean } & & $50.11 \pm 0.71 \mathrm{D}$ & $49.80 \pm 0.35 \mathrm{E}$ & $6.19 \pm 0.17 A$ & $5.89 \pm 0.09 \mathrm{C}$ \\
\hline & Control & $51.83 \pm 0.08 \mathrm{ab}$ & $50.92 \pm 0.22 \mathrm{c}$ & $6.20 \pm 0.03 \mathrm{bc}$ & $5.68 \pm 0.10 \mathrm{i}$ \\
\hline \multirow{3}{*}{ Poplar } & Lignin & $52.34 \pm 0.13 \mathrm{a}$ & $51.55 \pm 0.02 \mathrm{ab}$ & $6.22 \pm 0.01 \mathrm{~b}$ & $5.91 \pm 0.01 \mathrm{fg}$ \\
\hline & Mineral fertilization & $51.66 \pm 0.13 \mathrm{ab}$ & $50.81 \pm 0.21 \mathrm{~cd}$ & $6.13 \pm 0.06 \mathrm{~cd}$ & $5.80 \pm 0.04 \mathrm{~h}$ \\
\hline & Mycorrhiza & $51.44 \pm 0.16 \mathrm{~b}$ & $50.55 \pm 0.23 \mathrm{de}$ & $6.16 \pm 0.04 \mathrm{c}$ & $5.68 \pm 0.03 \mathrm{hi}$ \\
\hline \multirow[t]{2}{*}{ Mean } & & $51.82 \pm 0.36 \mathrm{~A}$ & $50.96 \pm 0.41 \mathrm{~B}$ & $6.18 \pm 0.05 A$ & $5.77 \pm 0.11 \mathrm{D}$ \\
\hline & Control & $50.45 \pm 0.07 \mathrm{e}$ & $50.90 \pm 0.29 \mathrm{c}$ & $6.03 \pm 0.03$ ef & $6.05 \pm 0.02 \mathrm{e}$ \\
\hline \multirow{3}{*}{ Willow } & Lignin & $50.70 \pm 0.30 \mathrm{~d}$ & $50.22 \pm 0.33 \mathrm{e}$ & $6.08 \pm 0.10 \mathrm{de}$ & $5.90 \pm 0.03 \mathrm{fg}$ \\
\hline & Mineral fertilization & $51.25 \pm 0.13 \mathrm{bc}$ & $50.37 \pm 0.36 \mathrm{e}$ & $6.21 \pm 0.07 \mathrm{bc}$ & $5.85 \pm 0.01 \mathrm{~g}$ \\
\hline & Mycorrhiza & $50.50 \pm 0.38 \mathrm{de}$ & $50.84 \pm 0.31 \mathrm{~cd}$ & $6.09 \pm 0.01 \mathrm{~d}$ & $5.88 \pm 0.03 \mathrm{~g}$ \\
\hline Mean & & $50.73 \pm 0.40 \mathrm{BC}$ & $50.58 \pm 0.41 \mathrm{C}$ & $6.10 \pm 0.09 \mathrm{~B}$ & $5.92 \pm 0.08 \mathrm{C}$ \\
\hline
\end{tabular}

Explanation as in Table 1.

(6.19\% d.m., on average), and the highest hydrogen content in this species was found on the plot fertilised with lignin $(6.37 \%$ d.m.). The same effect was observed for poplar, where the highest hydrogen content was found in the biomass fertilised with lignin. The figure is, however, significantly lower than for black locust (0.15 p.p. lower). The significantly lowest $\mathrm{H}$ values in the three-year harvest cycle were found in the willow biomass $(6.10 \% \mathrm{~d} . \mathrm{m}$. on average). Contrarily, the willow biomass in the four-year harvest cycle contained the highest values of hydrogen. Except for the control, where the value of this parameter was the highest, in the four-year cycle the significantly highest $\mathrm{H}$ content of all the soil enrichment options was found in the biomass harvested on the plots fertilised with lignin, both for willow and poplar (5.90 and 5.91\% d.m., respectively). With regard to black locust, the highest hydrogen content was found in the biomass harvested on the plot where mycorrhizal inoculation was applied $(6.03 \%$ d.m.). The differences in the H content in the black locust, poplar and willow biomass on plots where soil enrichment was applied, in comparison with the control plots, were -5.2 to $3.6,-1.1$ to 4 , and -3.3 to $3 \%$, respectively. The hydrogen content in the biomass of the species under study in the two-year harvest cycle was similar to that in the three-year cycle (Stolarski et al., 2013a). Like oxygen and carbon, hydrogen is an important component of biomass, which also affects the energy value due to the formation of water (Obernberger et al., 2006). SRWCs contains about 0.071.31 p.p. more $H$ than other biomass sources (Jenkins et al., 1998) and about 3 p.p. more than bituminous coal (Cuiping et al., 2004).

The highest sulphur content was found in black locust regardless of the harvest cycle. In the three-year harvest cycle, they were nearly twice as high as in poplar and willow (Table 6). The significantly highest sulphur content in this species was found in the biomass harvested on the plot with mineral fertilisation $(0.047$ and $0.052 \%$ d.m.). It is noteworthy that the $\mathrm{S}$ content did not increase as compared to the control only in the lignin and mycorrhiza option in the four-year harvest cycle; on the contrary, it dropped (by 0.016 and 0.005 p.p., respectively). In the other options, the differences in the content of this element in the black locust biomass was significantly higher. The average $\mathrm{S}$ content in the poplar and willow biomass was similar, and they were in the same homogeneous group regardless of the harvest cycle. However, except for the plots with lignin and mineral fertilisation in the four-year harvest cycle for poplar (an increase in the S content by 0.005 p.p., in both objects), 
Table 6. S and N content in SRWC biomass

\begin{tabular}{|c|c|c|c|c|c|}
\hline \multirow{3}{*}{ Species (A) } & \multirow{3}{*}{ Soil enrichment (B) } & \multicolumn{4}{|c|}{ Harvest cycle (C) } \\
\hline & & Three-year & Four-year & Three-year & Four-year \\
\hline & & \multicolumn{2}{|c|}{$\mathrm{S}(\%$ d.m.) } & \multicolumn{2}{|c|}{$\mathrm{N}$ (\% d.m.) } \\
\hline \multirow{4}{*}{ Black locust } & Control & $0.033 \pm 0.001 \mathrm{c}$ & $0.036 \pm 0.004 \mathrm{~b}$ & $1.117 \pm 0.034 \mathrm{~b}$ & $1.027 \pm 0.026 \mathrm{bc}$ \\
\hline & Lignin & $0.035 \pm 0.001 \mathrm{bc}$ & $0.020 \pm 0.002 \mathrm{ef}$ & $1.128 \pm 0.024 \mathrm{~b}$ & $0.956 \pm 0.007 \mathrm{c}$ \\
\hline & Mineral fertilization & $0.047 \pm 0.011 \mathrm{ab}$ & $0.052 \pm 0.002 \mathrm{a}$ & $1.321 \pm 0.024 \mathrm{a}$ & $1.129 \pm 0.022 \mathrm{~b}$ \\
\hline & Mycorrhiza & $0.047 \pm 0.011 \mathrm{ab}$ & $0.031 \pm 0.001 \mathrm{~cd}$ & $1.127 \pm 0.010 \mathrm{~b}$ & $1.064 \pm 0.024 \mathrm{bc}$ \\
\hline \multirow[t]{2}{*}{ Mean } & & $0.040 \pm 0.010 \mathrm{~A}$ & $0.035 \pm 0.012$ B & $1.173 \pm 0.092 \mathrm{~A}$ & $1.044 \pm 0.068 \mathrm{~B}$ \\
\hline & Control & $0.024 \pm 0.001 \mathrm{de}$ & $0.022 \pm 0.002 \mathrm{e}$ & $0.518 \pm 0.002 \mathrm{~d}$ & $0.438 \pm 0.016 \mathrm{ef}$ \\
\hline \multirow{3}{*}{ Poplar } & Lignin & $0.021 \pm 0.001 \mathrm{e}$ & $0.027 \pm 0.001 \mathrm{~d}$ & $0.653 \pm 0.006 \mathrm{~cd}$ & $0.470 \pm 0.026 \mathrm{de}$ \\
\hline & Mineral fertilization & $0.022 \pm 0.001 \mathrm{e}$ & $0.027 \pm 0.001 \mathrm{~d}$ & $0.524 \pm 0.006 \mathrm{~d}$ & $0.447 \pm 0.008 \mathrm{e}$ \\
\hline & Mycorrhiza & $0.023 \pm 0.002 \mathrm{e}$ & $0.019 \pm 0.001 \mathrm{f}$ & $0.465 \pm 0.012 \mathrm{de}$ & $0.405 \pm 0.007 \mathrm{f}$ \\
\hline \multirow[t]{2}{*}{ Mean } & & $0.022 \pm 0.001 \mathrm{C}$ & $0.024 \pm 0.004 \mathrm{C}$ & $0.540 \pm 0.072 \mathrm{C}$ & $0.440 \pm 0.028 D$ \\
\hline & Control & $0.028 \pm 0.001 \mathrm{~d}$ & $0.026 \pm 0.003 \mathrm{~d}$ & $0.455 \pm 0.009 \mathrm{e}$ & $0.475 \pm 0.023 \mathrm{de}$ \\
\hline \multirow{3}{*}{ Willow } & Lignin & $0.024 \pm 0.001 \mathrm{de}$ & $0.022 \pm 0.001 \mathrm{e}$ & $0.442 \pm 0.021 \mathrm{e}$ & $0.351 \pm 0.001 \mathrm{gh}$ \\
\hline & Mineral fertilization & $0.019 \pm 0.001 \mathrm{f}$ & $0.020 \pm 0.003 \mathrm{ef}$ & $0.385 \pm 0.002 \mathrm{fg}$ & $0.374 \pm 0.012 \mathrm{~g}$ \\
\hline & Mycorrhiza & $0.024 \pm 0.001 \mathrm{de}$ & $0.023 \pm 0.001 \mathrm{de}$ & $0.457 \pm 0.002 \mathrm{e}$ & $0.333 \pm 0.004 \mathrm{~h}$ \\
\hline Mean & & $0.024 \pm 0.003 \mathrm{C}$ & $0.023 \pm 0.003 \mathrm{C}$ & $0.435 \pm 0.032 \mathrm{D}$ & $0.383 \pm 0.058 \mathrm{E}$ \\
\hline
\end{tabular}

Explanation as in Table 1.

the $\mathrm{S}$ content in biomass harvested on the other plots was lower compared to the control, from 0.001 to 0.003 p.p. for poplar and from 0.003 to 0.009 p.p. for the willow biomass. The lowest $\mathrm{S}$ value in the willow biomass was found in the biomass obtained on the plots with mineral fertilisation, in contrast to poplar and black locust, where the S level was the highest on the plot with this soil enrichment option. The differences in the $\mathrm{S}$ content in the black locust, poplar and willow biomass on plots with soil enrichment, compared to the control plots, were -55 to $44,-14$ to 23 , and -47 to $-17 \%$, respectively. Compared to other research based on a two-year harvest cycle, the $\mathrm{S}$ content in the black locust, poplar and willow biomass in this study was lower by 0.021-0.026, 0.008-0.01 and 0.008-0.009 p.p., respectively (Stolarski et al., 2013a). The aforementioned is a beneficial change because it must be emphasised that sulphur is an unwanted element in biomass intended for thermal combustion, as it contributes to the corrosion of equipment and the fouling of boiler surfaces (Baxter et al., 1998; Obernberger et al., 2006). SRWCs can contain ten times less sulphur when compared to other sources of biomass (Jenkins et al., 1998) and even up to twenty times less than bituminous coal (Cuiping et al., 2004). This obviously makes SRWC- sourced biomass advantageous because a high $\mathrm{S}$ content in a fuel contributes to air pollution with $\mathrm{SO}_{\mathrm{x}}$ (Obernberger and Thek, 2004).

As far as nitrogen is concerned, significantly lower values were found in biomass in the four-year harvest cycle in all of the species (Table 6). As with the $\mathrm{S}$ content, the black locust biomass contained the highest content of this element - over twice as much as poplar and willow biomass. The significantly highest $\mathrm{N}$ content in this species was found in the biomass on the plot with mineral fertilisation $(1.321 \%$ d.m.). The $\mathrm{N}$ content increased in all of the plots where the soils were enriched, except on the plot where lignin was applied $(0.956 \%$ d.m. $)$. However, the $\mathrm{N}$ content was the highest $(0.653 \%$ d.m. $)$ in the poplar biomass on the plot with this soil enrichment option. The lowest $\mathrm{N}$ content in this species in both rotation cycles was found in the biomass harvested on plots with mycorrhizal inoculation, but the nitrogen content was higher in the biomass from the other plots compared to the control. On the other hand, the $\mathrm{N}$ content in the willow biomass was lower or was in the same homogeneous group as the biomass from the control plots (Table 6). The lowest nitrogen content was found in the biomass from the plot with mineral fertilisation in the three-year cycle and with mycorrhizal inoculation in the 
Table 7. Original and rotated (Varimax rotation) factorial loadings

\begin{tabular}{|c|c|c|c|c|c|c|}
\hline \multirow{2}{*}{ Feature } & \multicolumn{3}{|c|}{ Original } & \multicolumn{3}{|c|}{ Varimax rotation } \\
\hline & F1 & F2 & F3 & $\mathrm{F} 1$ & F2 & F3 \\
\hline Moisture & 0.96 & 0.06 & 0.03 & -0.95 & 0.18 & -0.01 \\
\hline Ash & 0.51 & -0.67 & -0.16 & -0.32 & 0.79 & 0.09 \\
\hline Higher heating value (HHV) & 0.93 & -0.24 & 0.06 & -0.84 & 0.46 & -0.07 \\
\hline Lower heating value (LHV) & -0.96 & -0.08 & -0.03 & 0.95 & -0.15 & 0.00 \\
\hline Volatile matter (VM) & -0.28 & 0.93 & 0.12 & 0.05 & -0.97 & -0.02 \\
\hline Fixed carbon (FC) & 0.11 & -0.90 & 0.15 & 0.10 & 0.88 & -0.25 \\
\hline $\mathrm{C}$ & 0.78 & 0.15 & -0.50 & -0.77 & 0.10 & 0.53 \\
\hline $\mathrm{H}$ & -0.11 & 0.18 & -0.96 & 0.11 & -0.10 & 0.97 \\
\hline S & -0.68 & -0.48 & -0.08 & 0.78 & 0.31 & 0.01 \\
\hline $\mathrm{N}$ & -0.78 & -0.49 & -0.28 & 0.89 & 0.31 & 0.21 \\
\hline Eigenvalue $\left(\lambda_{\mathrm{i}}\right)$ & 4.76 & 2.71 & 1.32 & 4.63 & 2.81 & 1.34 \\
\hline $\begin{array}{l}\text { Percentage of explained } \\
\text { variance }\end{array}$ & 47.58 & 27.07 & 13.17 & 46.33 & 28.13 & 13.36 \\
\hline
\end{tabular}

Bold indicate significant coefficients, significant at $\mathrm{p}<0.05$.

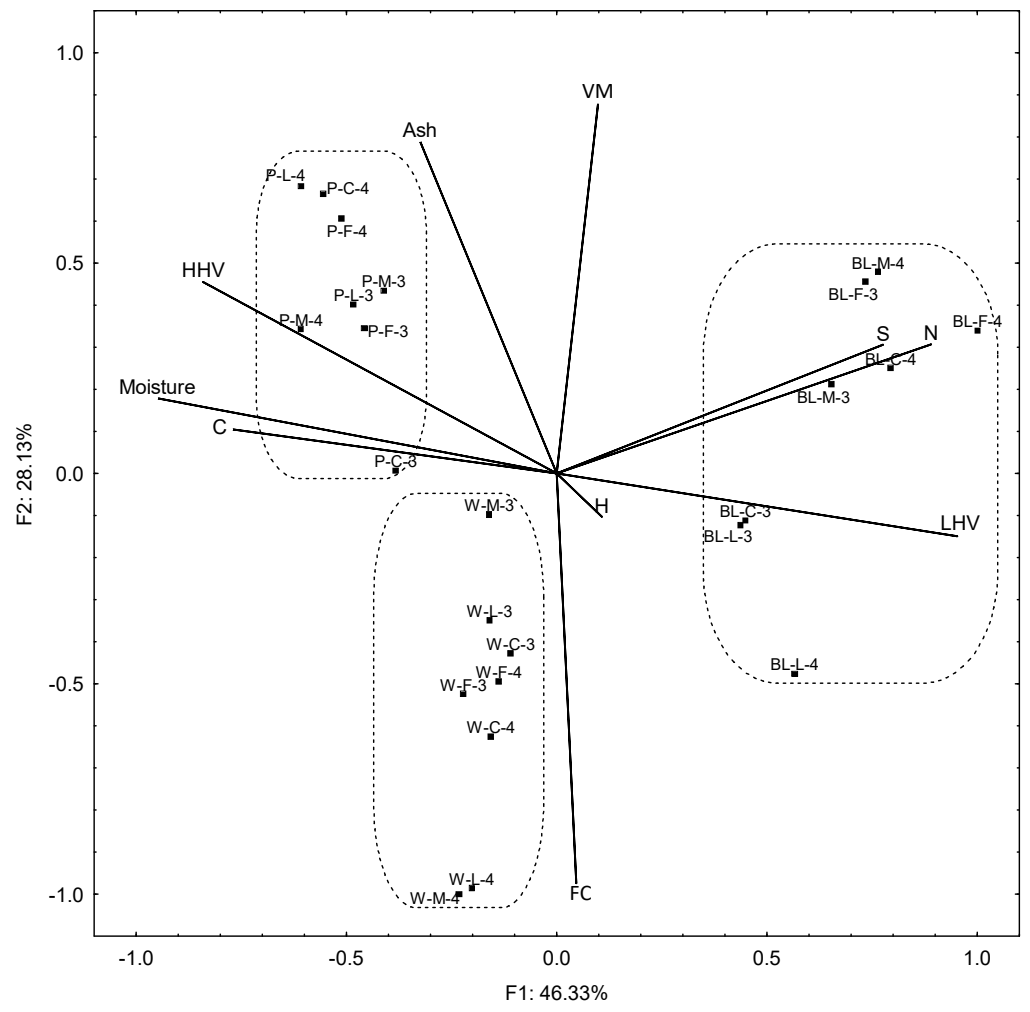

Fig. 1. Biplot. 
four-year harvest cycle $(0.385$ and $0.333 \%$ d.m., respectively). Differences in the $\mathrm{N}$ content in the black locust, poplar and willow on plots where soil enrichment was applied were -6.9 to $18.3,-10$ to 26.1 , and -30 to $0.4 \%$, respectively. Compared to the two-year harvest cycle, the $\mathrm{N}$ content in the black locust, poplar and willow biomass as found in this study was lower by $0.127-0.256,0.03-0.13$ and 0.045-0.097 p.p., respectively (Stolarski et al., 2013a). Nitrogen in SRWCs intended for thermal combustion is as unwanted an element as sulphur. It contributes to $\mathrm{NO}_{\mathrm{x}}$ emissions, which is particularly significant when the $\mathrm{N}$ content in biomass exceeds $0.6 \%$ d.m. (Obernberger et al., 2006). The results of the experiment in this study have shown that the poplar and willow biomass contains lower values and from this perspective - these are better fuels than the other source of biomass (Jenkins et al., 1998; Lalak et al., 2016; Obernberger et al., 2006) and bituminous coal (Cuiping et al., 2004).

The principal component analysis identified three principal components: F1, F2, F3, which in total, explained $87.82 \%$ of the variability (Table 7 ). The first component was the most strongly linked with moisture content and LHV, followed by N, HHV and S. This component explained the highest proportion (over 46\%) of the variation, and on the biplot diagram it separated black locust from the other two species (Fig. 1). Black locust contained a moisture low content, which resulted in high LHV. Moreover, the biomass of this species contained the highest values of $\mathrm{N}$ and $\mathrm{S}$. The other component, F2, separated poplar from willow on the basis of volatile substances, as well as fixed carbon and ash. Willow was characterised by high FC values, and, in consequence, a low VM content. Although HHV for poplar wood was the highest, its LHV was the lowest and the ash content was also the highest. The F2 principal component explained $28.13 \%$ of the variability. The third component F3 provided information about hydrogen content, which constituted over $13 \%$ of the variation.

\section{CONCLUSIONS}

1. The differences in thermophysical parameters and elemental composition varied greatly from one species to another, and this was highly affected by different soil enrichment practices in both harvest cycles. However, it is difficult to tell whether the effect was positive or negative. It depends mainly on the branch of industry which uses the biomass, because different properties can be important for thermal combustion than in the production of liquid biofuels.

2. The black locust biomass was the most greatly varied in terms of its quality on the plots where soil enrichment was applied for volatile matter, fixed carbon, $\mathrm{C}, \mathrm{H}$ and $\mathrm{S}$ content.
3. The greatest differences in the poplar biomass were shown for higher heating value and ash content. Furthermore, the willow biomass was more varied than other species in terms of the $\mathrm{N}$ content.

4. Although the results show significant changes in quality parameters of the species biomass on the plots where soil enrichment was applied, further studies in this regard are necessary to confirm the relationships in further harvest rotations.

Conflict of interest: The Authors do not declare conflict of interest.

\section{REFERENCES}

Acquah G.E., Krigstin S.G., Wetzel S., Cooper P., and Cormier D., 2015. Heterogeneity of forest harvest residue from Eastern Ontario Biomass Harvests. Forest Prod. J., doi: 10.13073/FPJ-D-14-00098

AEBIOM, 2015. AEBIOM Statistical Report - European Bioenergy Outlook. Key findings, Brussels.

Baxter L.L., Miles T.R., Miles Jr T.R., Jenkins B.M., Milne T., Dayton D., Bryerse R.W., and Odenf L.L., 1998. The behavior of inorganic material in biomass-fired power boilers: field and laboratory experiences. Fuel Process. Technol., 54, 47-78.

Blanco-Canqui H., 2010. Energy Crops and Their Implications on Soil and Environment. Agron. J., 102, 403-419, doi:10.2134/agronj2009.0333

Bowen B.H. and Irwin M.W., 2008. Coal characteristics. CCTR Basic Facts File \# 8. https://www.purdue.edu/discoverypark/energy/assets/pdfs/cctr/outreach/Basics8-CoalCharacteristics-Oct08.pdf

Cuiping L., Chuangzhi W., Yanyongjie, and Haitao H., 2004. Chemical elemental characteristics of biomass fuels in China. Biomass Bioenergy, 27, 119-130.

Di Muzio Pasta V., Negri M., Facciotto G., Bergante S., and Maggiore T.M., 2007. Growth dynamic and biomass production of 12 poplar and two willow clones in a short rotation coppice in northern Italy. 15th European Biomass Conf. Exhibition, from Research to Market Deployment. Proc. Int. Conf. Held in Berlin, Germany.

Dincer I., and Zamfirescu C., (Eds), 2014. Advanced power generation systems. Chapter 3 - Fossil Fuels and Alternatives. Elsevier, Amsterdam, NL.

Fengel D. and Wegener G., 1989. Wood. Chemistry, Ultrastructure, Reactions. Walter de Gruyter, Berlin-New York.

Freire M., Lopes H., and Tarelho L.A.C., 2015. Critical aspects of biomass ashes utilization in soils: Composition, leachability, PAH and PCDD/F. Waste Manag., 46, 304-315.

Gasol C.M., Brun F., Mosso A., Rieradevall J., and Gabarrell X., 2010. Economic assessment and comparison of acacia energy crop with annual traditional crops in Southern Europe. Energy Policy, 38, 1, 592-597

Greenhalf C.E., Nowakowski D.J., Bridgwater A.V., Titiloye J., Yates N., Riche A., and Shield I., 2012. Thermochemical characterisation of straws and high yielding perennial grasses. Ind. Crop. Prod., 36,1, 449-459. 
IEA, 2016. Bioenergy. About bioenergy. https://www.iea.org/ topics/renewables/subtopics/-bio-energy/ (acessed 20 Jun. 2016).

ISO 18134-1:2015. Solid Biofuels - Determination of Moisture Content - Oven Dry Method - Part 1: Total Moisture Reference Method. International Organization for Standardization, Switzerland.

ISO 16948:2015. Solid Biofuels - Determination of Total Content of Carbon, Hydrogen and Nitrogen. International Organization for Standardization, Switzerland.

ISO 16994:2015. Solid Biofuels - Determination of Total Content of Sulfur and Chlorine. International Organization for Standardization, Switzerland.

ISO 18122:2015. Solid Biofuels - Determination of Ash Content. International Organization for Standardization, Switzerland.

ISO 1928:2009. Solid Mineral Fuels - Determination of Gross Calorific Value by the Bomb Calorimetric Method and Calculation of Net Calorific Value. International Organization for Standardization, Switzerland.

Jameel H., Keshwani D.R., Carter S.F., and Treasure T.H., 2010. In. J. Cheng, editor, Biomass to renewable energy processes. CRC Press, Boca Raton, FL.

Jenkins B.M., Baxter L.L., Miles Jr. T.R., and Miles T.R., 1998. Combustion properties of biomass. Fuel Process. Technol., 54, 17-46.

Kopetz H., Jossart J., Ragossnig H., and Metschina C., 2007. European Biomass Statistics 2007. European Biomass Association. Brussels.

Krzyżaniak M., Stolarski M. J., Waliszewska B., Szczukowski S., Tworkowski J., Załuski D., and Śnieg M., 2014. Willow biomass as feedstock for an integrated multi-product biorefinery. Ind. Crop. Prod., 58, 230-237

Lalak J., Martyniak D., Kasprzycka A., Zurek G., Moron W., Chmielewska M., Wiącek D., and Tys J., 2016. Comparison of selected parameters of biomass and coal. Int. Agrophys., 30, 475-482, doi: 10.1515/intag-2016-0021

Manzone M., Bergante S., and Facciotto G., 2015. Energy and economic sustainability of woodchip production by black locust (Robinia pseudoacacia L.) plantations in Italy. Fuel, 140, 555-560.

Matyka M. and Kuś J., 2016. Influence of soil quality for yielding and biometric features of Miscanthus $x$ Giganteus. Pol. J. Environ Stud., 25, 1, 213-219.

Mitsui Y., Seto S., Nishio M., Minato K., Ishizawa K., and Satoh S., 2010. Willow clones with high biomass yield in short rotation coppice in the southern region of Tohoku district (Japan). Biomass Bioenergy, 34, 4, 467-473.

Njakou Djomo S., Ac A., Zenone T., De Groote T., Bergante S., Facciotto G., Sixto H., Ciria Ciria P., Weger J., and Ceulemans R., 2015. Energy performances of intensive and extensive short rotation cropping systems for woody biomass production in the EU. Renew. Sust. Energ. Rev., $41,845-854$

Njakou Djomo S., El Kasmioui O., De Groote T., Broeckx L.S., Verlinden M.S., Berhongaray G., Fichot R., Zona
D., Dillen S.Y., King J.S., Janssens I.A., and Ceulemans R., 2013. Energy and climate benefits of bioelectricity from low-input short rotation woody crops on agricultural land over a two-year rotation. Appl. Energy, 111, 0, 862-870.

Obernberger I., Brunner T., and Bärnthaler G., 2006. Chemical properties of solid biofuels-significance and impact. Biomass Bioenergy, 30: 973-982.

Obernberger I. and Thek G., 2004. Physical characterisation and chemical composition of densified biomass fuels with regard to their combustion behavior. Biomass Bioenergy, 27, 653-669.

Sabatti M., Fabbrini F., Harfouche A., Beritognolo I., Mareschi L., Carlini M., Paris P., and ScarasciaMugnozza G., 2014. Evaluation of biomass production potential and heating value of hybrid poplar genotypes in a short-rotation culture in Italy. Ind. Crop. Prod., 61, 62-73.

Slade R., Saunders R., Gross R., and Bauen A., 2011. Energy from biomass: the size of the global resource. Imperial College Centre for Energy Policy and Technology and UK Energy Research Centre, London, UK.

Stolarski M.J., Krzyżaniak M., Warmiński K., and Niksa D., 2016. Energy consumption and costs of heating a detached house with wood briquettes in comparison to other fuels. Energ. Convers. Manag., 121: 71-83.

Stolarski M.J., Krzyżaniak M., Szczukowski S., Tworkowski J., and Grygutis J., 2015a. Changes of the quality of willow biomass as renewable energy feedstock harvested with biobaler. J. Elem., 20, 3, 717-730.

Stolarski M.J., Krzyżaniak M., Szczukowski S., Tworkowski J., Załuski D., Bieniek A., and Gołaszewski J., 2015b. Effect of increased soil fertility on the yield and energy value of short-rotation woody crops. Bioenerg. Res., 8, 1136-1147.

Stolarski M.J., Krzyżaniak M., Waliszewska B., Szczukowski S., Tworkowski J., and Zborowska M., 2013a. Lignocellulosic biomass derived from agricultural land as industrial and energy feedstock. Drewno. Pr. Nauk. Donies. Komunik., 55, 189, 5-23.

Stolarski M.J., Szczukowski S., Tworkowski J., and Klasa A., 2013b. Yield, energy parameters and chemical composition of short-rotation willow biomass. Ind. Crop. Prod., 46, 60-65.

Straker K.C., Quinn L.D., Voigt T.B., Lee D.K., and Kling G.J., 2015. Black Locust as a Bioenergy Feedstock: a Review. Bioenerg. Res., 8, 3, 1117-1135.

Weger J., Vávrová K., Kaśparová L., Bubenik J., and Komárek A., 2013. The influence of rotation length on the biomass production and diversity of ground beetles (Carabidae) in poplar short rotation coppice. Biomass Bioenergy, 54, 284-292. 